\title{
Estudos BBBEP
}

\section{Ações inclusivas no ensino superior brasileiro}

Jefferson Olivatto da Silva

\section{Resumo}

Partindo de uma concepção etnográfica das práticas escolares da Universidade Estadual do Centro-Oeste (Unicentro-PR), constatou-se a dinâmica de grupos relativa às interações e fronteiras simbólicas que permeavam as aprendizagens. Esses processos abrangiam o ciclo espaciotemporal do ensino superior: acesso, permanência e sucesso inseridos em uma comunidade de aprendizagem ampla. Nesse sentido, um programa foi desenvolvido para coordenar as ações que pudessem desdobrar as aprendizagens em termos de medidas pedagógicas inclusivas nas interações pedagógicas, funcionais e administrativas, compreendendo o espaço universitário como uma comunidade de aprendizagem ampla, que oferece diversas fontes para otimizar a formação profissional e acadêmica.

Palavras-chave: antropologia educacional; pesquisa/ação; inclusão; aprendizagem. 


\section{Abstract \\ Inclusive actions in Brazilian higher education}

Based on an ethnographical conception of school practices applied in Universidade Estadual do Centro-Oeste (Unicentro), in the state of Paraná, group dynamics related to the interactions and symbolic boundaries that permeated learning were verified. These processes included the time-space conception of higher education: access, permanence and success inserted in a community of ample learning. Thus, a program was developed in order to coordinate actions that could unfold the learning processes in terms of inclusive measures among pedagogical, functional and administrative interactions, conceiving the university space as a broad learning community, which offers different sources to maximize professional and academic formation.

Keywords: educational anthropology; action research; inclusion; learning.

\section{Introdução}

O ensino superior, em sua concepção de formação de profissionais que desenvolvam, estimulem e ampliem as áreas de ciências, tecnologias e cultura, tem como legitimidade social o diploma expedido por instituições reconhecidas pelo Ministério de Educação (MEC) e, para os cursos que contam com conselhos profissionais, é necessário que os diplomas sejam enviados para o reconhecimento de pertença aos referidos grupos, como aponta a Lei de Diretrizes e Bases da Educação Nacional (Brasil. Lei n ${ }^{\circ}$ 9.394, 1996), norte legitimador da educação brasileira. Os fatores de legitimidade social devem ser o foco da modalidade da educação superior como questão a ser especificada na formação universitária de alunos com necessidades especiais.

Em meio à complexidade administrativa e didática, haja vista que se deve ter em mente que há pouca informação e poucas práticas educativas inclusivas voltadas diretamente ao ensino superior, pretendeu-se partilhar a experiência de implantação de uma política inclusiva à frente de um programa universitário. Assim, vislumbrou-se um programa que tivesse como mote central medidas pedagógicas inclusivas para essa modalidade de ensino. O aluno é refletido como aquele que precisa ter acesso às informações referentes ao cotidiano acadêmico e às diferentes abordagens e teorias, pelo menos, pertencentes ao curso matriculado. Nesse sentido, a inclusão precisa criar novas perspectivas no funcionamento institucional para que a totalidade de seus alunos tenha a garantia de sua formação profissional, científica, cultural e tecnológica, como pressupõe a LDB. 
Este debate sobre a inclusão no ensino superior tem como pano de fundo a coordenação de um novo programa que atendeu alunos com necessidades educacionais especiais durante um período de 24 meses, entre os anos de 2010 e 2012. Tomando por base outras experiências em pesquisas pedagógicas (Glat, 2011; Silva, 2012), empregou-se a etnografia educacional para o desenvolvimento desse novo programa. Felizmente, a instituição já possuía programa de apoio cujo enfoque eram os alunos com deficiência sensorial, surdez e cegueira. Contando com o suporte administrativo da instituição, foi confiada a tarefa de administrar a política de inclusão da Universidade Estadual do Centro-Oeste (Unicentro), Paraná, no sul do Brasil, com o auxílio da extensão do programa já existente nos campi do Centro de Desenvolvimento Tecnológico de Guarapuava (Cedeteg) e na cidade de Irati.

Em termos espaciais, a dinâmica institucional da Unicentro deve ser considerada pelo conjunto dos 32 cursos de graduação, articuladores de suas pós-graduações lato sensu e stricto senso. Além dos seus três campi universitários, a Universidade possui mais quatro campi avançados - Chopinzinho, Laranjeiras do Sul, Pitanga e Prudentópolis - e polos de educação a distância - Bituruna, Palmital, Coronel Vivida, Goioerê e Paranavaí.

Para entender os nativos da Unicentro atendidos pelo programa, é preciso contextualizar a dinâmica institucional que especifica a complexidade da inclusão no ensino superior, tanto pela historicidade inclusiva da Universidade quanto por conversas exploratórias com os grupos internos, para então ser observada a instalação do novo programa. A instituição foi examinada tendo por base dois momentos: no primeiro, a etnografia foi utilizada para constatar a aprendizagem enquanto fenômeno decorrente de múltiplas interações e ambientes institucionais; no segundo, em virtude da operacionalidade do que fora constatado na constituição de grupos, ambientes e sua interação, foi desenvolvida uma proposição por meio da pesquisa-ação (Tripp, 1993; Oliveira; Santos, 2005; Glat, 2011), visando a processos de aprendizagens descentralizados, isto é, fontes de aprendizagens que estão além da relação professor e aluno em sala de aula.

Como será apresentado pela pesquisa-ação, o programa passou do atendimento restrito aos alunos com determinadas necessidades para o atendimento mais abrangente, o que não significou a resolução de todas as questões relativas à aprendizagem do alunado, mas sim o aprimoramento de ações que hodiernamente precisam ser realizadas enquanto medidas institucionais inclusivas.

Com efeito, o universo simbólico também é assegurado pela fronteira temporal característica do ciclo do ensino superior, que compreende o acesso, a permanência e o sucesso. Esses três momentos apresentam características educacionais interatuantes do ciclo. O acesso promovido pelo vestibular caracteriza a escolha institucional dos atributos que os alunos deveriam ter incorporado dos ciclos escolares anteriores, ao passo que o sucesso seria a legitimação dos atributos que seriam determinantes para a conclusão do ciclo formativo. Todavia, o entremeio ainda era 
o ponto ascendente das reivindicações de adaptação do alunado, pois apenas alguns processos de aprendizagens institucionais detinham o reconhecimento dos atributos que deveriam ser assimilados. Esses processos figuravam os impasses da inclusão em seu todo, tanto para restringir a permanência quanto a atuação profissional.

Nossa atitude de entendimento antropológico da aprendizagem significou retirar a ênfase da sala de aula como o único espaço ou o espaço ideal de aprendizagem. O campus universitário oportuniza, em sua totalidade, circunstâncias para que os alunos tenham acesso a elementos culturais, tecnológicos, científicos e humanos, desdobrando as aprendizagens cuja exposição lhes é cotidiana. Pensando na descentralidade dos processos cognitivos, afetivos e sociais, a instituição universitária foi concebida na qualidade de comunidade de aprendizagem, cujos nativos são alunos, professores, estagiários e funcionários com necessidades especiais ou não. Perante essa dinâmica, os estudos etnográficos relativos à interação de grupos étnicos (Barth, 2000; Pozo, 2002; Cunha, 2010) puderam ser utilizados no meio educacional para a compreensão de autoatribuições, interações de interesses específicos e articulações institucionais a fim de que fosse compreendida a dinâmica universitária: diferentes interesses perpassam o cotidiano escolar, que, por meio de uma historicidade, congrega ações promotoras da formação profissional, tecnológica, científica e cultural. Mesmo havendo distâncias entre cursos, setores, professorado, alunado e projetos de pesquisa e extensão, há legitimadores, como o Ministério da Educação (MEC) e a Secretaria da Ciência, Tecnologia e Ensino Superior (Seti) do Paraná, para pré-determinar o modelo educacional e administrativo.

À medida que o programa conseguia identificar sinais predominantes dessas interações e seus respectivos atores, a universidade poderia responder por uma política inclusiva efetiva. Embora sem a configuração de grupos étnicos, a utilização desses estudos antropológicos na educação demostra de que maneira os vínculos e interesses entre atores denotam limites e noções de aprendizagem.

\section{O cotidiano do ensino superior}

A chegada de alunos com necessidades especiais à universidade precisa ser compreendida para além do caráter inclusivo, posto que os antigos ambientes de ensino restritos deixaram de ser os únicos em que o aluno teria acesso ao conhecimento e buscaria "ser alguém" (D'Ávila et al., 2011), quer pelo signo social que implica ser universitário, quer pela identidade profissional em busca de trabalho. Os conflitos entre aprendizagem, capacitação docente e adaptação ao ensino têm gerado novas situações às IES que há duas décadas eram circunstanciais ou esporádicas: educação do campo, educação ambiental, educação sexual, violência escolar, precarização dos estabelecimentos de ensino etc. A educação especial inseriu-se nesse mesmo panorama universitário, 
deixando de ser uma área específica a poucos - familiares e profissionais de instituições especiais - para se tornar temática presente no ensino superior para professores, alunos, funcionários e estagiários (Martins, 2000).

A necessidade de o ensino superior despender maior atenção sobre a educação especial ocorreu por novas políticas de inclusão que fomentaram a inversão da proporção da matrícula de alunos com necessidades especiais, que em 1998 era de 87,0\% nas escolas especializadas e classes especiais sobre $13,0 \%$ de matrículas em escolas comuns e classes regulares. Embora isso representasse um abalo no investimento estatal nos centros especializados, no censo do Instituto Nacional de Estudos e Pesquisas Educacionais Anísio Teixeira (Inep) de 2009, 60,5\% dos alunos passaram a ter suas matrículas nas escolas comuns e classes regulares sobre $39,5 \%$ nas escolas especializadas e classes especiais, o que pressupunha a política de inclusão anunciada pela LDB. Com essa característica, o alunado com necessidades especiais e seus familiares, assimilaram novos atributos às possibilidades de aprendizagem, pois participavam de instituições escolares em que informações sobre o ensino superior estavam disponíveis: investimentos em tecnologias de comunicação, capacitação do professorado (especialização, mestrado e doutorado), aumento do número de vagas em instituições públicas federais no período noturno e crescimento da modalidade a distância nas universidades públicas. Vale lembrar que o investimento em educação aumentou substancialmente, pois a Coordenação de Aperfeiçoamento de Pessoal de Nível Superior (Capes) passou a contar com um orçamento de 2,66 bilhões em 2009, superior ao anterior orçamento de 0,85 bilhão, estabelecido em 1998 (Brasil. Inep, 2009).

As leis de que os núcleos e programas de apoio lançam mão para as políticas inclusivas, geralmente, precisam de um alargamento interpretativo para que se possa contemplar o ensino superior, considerando as especificidades elaborativas da legislação, voltadas quer para o ensino fundamental e médio - LDB (Brasil. Lei $n^{\circ}$ 9.394, 1996), que regulamenta a educação brasileira, Lei no 10.172, de 09 de janeiro de 2001, que aprova o Plano Nacional de Educação, que reúne metas e objetivos para a educação dos alunos com necessidades especiais - quer para concursos ou políticas nacionais de inclusão, como as Leis n ${ }^{\circ} 10.048$, de 08 de novembro de 2000 e no 10.098, de 19 de dezembro de 2000, regulamentadas pelo Decreto no 5.296 , de 02 de dezembro de 2004.

Observou-se que as barreiras pedagógicas no ensino superior reproduzem a naturalização da educação básica como suposta limitação de aprendizagem ao alunado com necessidades especiais, segundo préjulgamentos do modelo avaliativo e autoavaliativo do ensino superior (Sampaio, 2000; Oliveira; Santos, 2005). Esse efeito socioeducativo reproduz sistemas educacionais que restringem qual alunado se pressupõe ensinar, bem como o direito de atuar em uma determinada área, o que caracteriza a menor legitimidade de acesso e de permanência no ensino superior. Mesmo o questionamento sobre a escolha do curso por um 
determinado alunado pressupõe não somente habilidades necessárias à área, mas uma concepção determinista de que o conhecimento possa ou não ser apropriado de acordo com a tipologia de aluno ou com o perfil, que é mais comumente descrito. Nesse sentido, a concepção de aprendizagem está vinculada a algum atributo cognoscível imutável que o aluno deve apresentar e sem o qual a aprendizagem é prejudicada ou impossibilitada.

As contradições do processo inclusivo nas IES, o acesso sem a devida preparação para formar, as restrições orçamentárias para mudanças arquitetônicas e comunicacionais e a não capacitação do corpo docente refletem a carência histórica e educacional em incluir alunos que fogem ao escopo das políticas educacionais e às epistemologias de aprendizagem com enfoque no desenvolvimento infantil. Constatou-se que isso ocorre pela ausência de instrumentos normativos que disciplinem a oferta de educação aos alunos com necessidades especiais no ensino superior. Assim, a Resolução CNE/CP n ${ }^{\circ}$ 1/2002 - art. 6º -, referente ao projeto pedagógico dos cursos de formação de docentes para a educação básica, que descreve a necessidade de conhecimentos, relativos à realidade da educação básica, a respeito das especificidades dos alunos com necessidades educacionais especiais, não possui iniciativa correspondente no âmbito da educação superior, nem suscita práticas pedagógicas executadas entre e para os grupos da universidade (Brasil. CNE/CP, 2002). Ademais, as concepções de desenvolvimento e aprendizagem que predominam na educação básica não podem ser simplesmente transpostas para a educação superior, pelo menos não em seu molde didático-pedagógico, impondo um estado de tutela e/ou dependência na relação professor-aluno. Talvez um dos equívocos reproduzidos é a crença amplificada no "estado de autonomia" que a educação fundamental pressupõe desenvolver, baseada em condição extemporânea às condições socioeconômicas, culturais e psicoafetivas necessárias para o desenvolvimento do aluno no processo educativo.

Com efeito, a compreensão do ensino superior, quando observado somente pela relação didático-pedagógica aluno-professor, gera desvios interpretativos ou simplificações pela insistência em que haja somente aprendizagem na sala de aula (Bisol et al., 2010), sem que se percebam as várias fontes pertencentes à comunidade universitária.

\section{A aprendizagem da cultura universitária}

Pensando sobre a necessidade de um tipo de atendimento especializado, a Unicentro criou o Programa de Apoio aos Alunos com Necessidades Especiais (Pape), em 2004, que funcionou no mesmo molde até o início de 2010. Durante esse período, foram desenvolvidas palestras e minicursos voltados diretamente ao grupo de alunos surdos e com cegueira ou baixa visão. Dessa forma, o foco era oferecer ações voltadas para a ampliação do conhecimento e interesse pela Língua Brasileira de Sinais (Libras), para a introdução ao braile e voltadas para leitores de provas e concursos. 
Outro programa criado pela Instituição foi o de tutoria, mantido pela Pró-Reitoria de Ensino, para auxiliar os alunos surdos e com cegueira ou baixa visão que precisavam de apoio pedagógico. Esse programa ainda funciona por candidatura voluntária de um tutor para cada aluno especial - sendo ambos do mesmo curso e ano -, cuja gratificação é uma bolsa para o tutor por 12 horas semanais de atividades, sob orientação e acompanhamento de um professor do respectivo departamento pedagógico.

No entanto, havia situações também administrativas e regionais que não possibilitavam inclusão ampla, posto que faltavam intérpretes de Libras capacitados na região, além da permanência de barreiras mantidas após o ingresso de alunos com diferentes especificidades. Era comum aos alunos com outras necessidades o desconhecimento do programa e aos professores o desconhecimento das implicações da inclusão na formação dos alunos. Com efeito, surgiam retenções e desistências, pois os professores não tinham a compreensão de que o processo de ensinoaprendizagem deveria ser realizado com o auxílio de medidas pedagógicas adaptativas, sem que se prejudicasse a formação profissional.

Não se deve esquecer que à medida que as aprendizagens são evidenciadas no cotidiano escolar, os diferentes momentos, espaços e oportunidades devem ser considerados para a compreensão de sua produção. A educação acrítica das IES e das outras modalidades escolares priorizam uma assepsia educacional, segundo a qual as aprendizagens não precisam relacionar-se com os condicionantes do seu alunado, por apreender o conhecimento como um traço da experiência humana, distante do cotidiano (Certeau, 2000; Bourdieu, 2008). Dessa forma, a descentralidade de aprendizagens, que foi enfatizada anteriormente, refere-se aos diferentes ambientes e interações correntes na instituição, mas que não atingem o patamar de aprendizagem formativa, como é proposto na relação assimétrica professor-aluno: eventos, palestras, minicursos, ambientes virtuais, semanas acadêmicas, amostras culturais, rádio e TV universitárias, boletins informativos entre outros.

Apoiando essa concepção, afirma Pozo (1999, p. 25):

Cada sociedade, cada cultura gera suas próprias formas de aprendizagem, sua cultura de aprendizagem [...] A relação entre o aprendiz e os materiais de aprendizagem está mediada por certas funções ou processos de aprendizagem, que se derivam da organização social dessas atividades e das metas impostas pelos instrutores ou professores.

Após três meses de conversas e reuniões com diferentes setores, alunos, professores, tutores e intérpretes, foram detectados os impasses acadêmicos dificultadores da inclusão, com os quais a Universidade deveria lidar para a composição de uma política inclusiva direcionada à especificidade do ensino superior. Nesse sentido, a aproximação com os grupos para constatar a dinâmica dessas contradições tornou possível 
remodelar o programa de apoio da Unicentro. Portanto, instituiu-se como seu pressuposto a operacionalização dos traços sociais utilizados pelos indivíduos e grupos em seu vínculo identitário para criar uma nova visibilidade social e propor ações que rompessem com as barreiras simbólicas e materiais de inclusão e exclusão da comunidade universitária (Barth, 2000; Pozo, 2002; Durham, 2010).

Foi priorizado o caráter de comunidade de aprendizagem para focar o desenvolvimento de uma política institucional de inclusão. Nesse momento, era preciso fazer uso da pesquisa-ação como instrumento de avaliação para a adequabilidade do programa, já que as demandas haviam sido constatadas nos grupos institucionais (Glat, 2011). Dessa forma, sem o conhecimento de sua dinâmica, as propostas inclusivas seriam externas às necessidades dos alunos; por outro lado, essa constatação precisava partir para uma intervenção de maneira efetiva, desdobrando-se em ações que superassem as fronteiras no cotidiano acadêmico.

Quanto ao acesso, os alunos surdos e cegos ou com baixa visão tinham o apoio de uma equipe específica para o vestibular, que contratava intérpretes de Libras e ledores de provas quando solicitado no ato da inscrição do concurso. Outras especificidades, como as relacionadas à limitação física ou a transtornos globais, não surgiram entre as solicitações dos candidatos, que provavelmente desconheciam seus direitos.

Em se considerando que a colação de grau é o fechamento do ciclo acadêmico, as adaptações de medidas pedagógicas seriam responsáveis por sua realização. No entanto, como foi constatado pelo histórico de atendimento aos alunos, esse momento tornou-se uma questão a ser pensada a respeito da inclusão, uma vez que alguns alunos com necessidades especiais não correspondiam aos moldes avaliativos e/ou pedagógicos. A forma mais elusiva e menos pedagógica, tradicional aos outros níveis educacionais, era a pretensa aprendizagem coletiva, visto que recaía no professor que reprovava seus alunos argumentar sobre sua atitude, e não nos professores que aprovavam.

Isso significava que, para não ter de alterar as estratégias de ensino e as formas de avaliação, seria mais conveniente a aprovação dos alunos ou a exclusão do alunado, por suas necessidades especiais, de modo que sua reprovação seria um mecanismo para justificar a pretensa incapacidade de corresponder ao exigido em sua profissão. Esse fenômeno pôde ser observado nos diálogos com departamentos e setores administrativos, quando as narrativas em torno de meritocracia e capacidades cognitivas eram naturalizadas, em decorrência de atributos que compunham fronteiras de exclusão, ao passo que o programa deveria atuar em suas orientações e ações na busca de estratégias inclusivas. Como argumento pedagógico e administrativo, a meritocracia somente seria válida se a história do ensino superior brasileiro fosse deslocada das condições socioeconômicas que explicam a dificuldade de acesso ou a falta de professores, e fossem priorizadas certas habilidades de determinados grupos e regiões. Além disso, todos os pré-requisitos que são impostos 
para que os alunos terminem o ensino básico não garantem a todos o acesso imediato.

A imputação de habilidades naturais, por seu turno, busca cercear a escolha dos indivíduos por certas habilidades: se for talentoso para esportes deve ser atleta ou fazer Educação Física; comunicativo precisa cursar Comunicação Social ou seguir carreira política; quem gosta de ler deve escolher a área de Humanas. Trata-se de argumentos defensivos e excludentes, por parte das autoridades didático-pedagógicas, de que se o aluno não tiver as supostas habilidades, deveria escolher outro curso. Se a independência do alunado - e não o caráter hierárquico escolar - fosse prezada, tanto na aquisição quanto na experiência, menor seria a tensão do professorado em buscar o lugar de expertise absoluto, a fim de mediar o alunado para as aprendizagens disponíveis. Foi preciso insistir que o direito à educação é anterior a qualquer mérito e capacidade natural, uma vez que corresponde à vivência plena de cidadania.

O programa anterior, desde sua origem enquanto Programa de Auxílio para Estudantes (Pape), em 2004, mantinha um braço no campus de Irati. Um dos serviços oferecidos aos alunos inscritos no programa era uma cota de 100 cópias de textos, disponível aos alunos surdos, que dominam ou não a Libras. Outro serviço era a ampliação ou a digitalização de textos para os alunos com cegueira ou baixa visão nos três campi universitários. Também, para o acompanhamento do conteúdo das disciplinas dos alunos falantes de Libras, o programa deixava à disposição dos intérpretes cópias dos textos da bibliografia para que tivessem em mãos o material a ser trabalhado em sala de aula.

Muito embora seja utilizada a adaptação dos diplomas legais sobre atendimento especial relacionados à educação básica, repete-se na prática a noção de que o ensino superior é uma continuidade do ensino médio, e não realmente outra modalidade de ensino. Por isso, concepções de aprendizagem ou de desenvolvimento utilizadas nas outras modalidades não podem ser simplesmente incorporadas no sistema universitário. Por conta da especificidade das práticas pedagógicas do ensino superior, observou-se que grande parcela do alunado desenvolveu habilidades que não ocorreram na educação básica.

Pela investigação dos grupos que compunham a comunidade interna, foi possível observar quais sinais identitários redesenhavam fronteiras (Barth, 2000). Esses sinais transitavam tanto internamente quanto externamente à universidade, significando empréstimos culturais, já que vinham de relações anteriores ao ingresso de seus atores na universidade (Cunha, 2010). Evidenciava-se que as relações externas de determinados grupos faziam-se presentes no cotidiano escolar, como era o caso da denominada comunidade surda, cujos vínculos eram mais intensos comparativamente a outros:

- Alunos falantes de Libras: os alunos tinham como prioridade no atendimento à inclusão a presença de intérpretes para auxiliá-los 
nos textos, nos trabalhos em grupo, nos estágios e nas diferentes avaliações. A maioria pertence à Pastoral Católica do Surdo.

- Professores surdos: formados em Pedagogia, pertencentes à Pastoral Católica do Surdo; ênfase no domínio de Libras e no acompanhamento de intérpretes durante reuniões institucionais.

- Intérpretes de Libras: com formação, em quase sua totalidade, em Licenciaturas, Pedagogia, especialização em educação, certificação da maioria pelo Pró-Libras. Atuam como intérpretes em outras instituições e participam da Pastoral Católica do Surdo e têm como interesse o reconhecimento do estatuto de professor - não de técnico -, algo que para eles poderia ser alcançado com atividades de pesquisa, ensino e extensão.

Os outros indivíduos que precisavam de atendimento e acompanhamento, em geral, não produziam vínculos mantidos pelo traço de necessidade especial, temporária ou permanente. No entanto, foi possível identificar similitudes com base em outros sinais, ora atribuídos pela instituição, ora por eles próprios. Por essa constatação, os sinais que abaixo são apresentados têm a função discriminatória, mesmo que não sejam exclusivos, mas orientam a justificativa de buscar auxílio no programa ou de ser encaminhado para ele:

- Alunos surdos oralizados: há heterogeneidade nas áreas do conhecimento e raros pedidos de tutoria.

- Alunos cegos ou com baixa visão: existe simpatia entre eles, mas não estabelecem vínculo intenso ou visível. Cursam Licenciaturas e fazem pedidos de tutoria e adaptações ambientais.

- Alunos com distúrbios psicoafetivos e psiquiátricos: raramente pedem tutoria, mas buscam auxílio para adaptação curricular quanto às avaliações e estágios, principalmente pela dificuldade em acompanhar o ritmo de determinadas disciplinas. Os alunos que buscam orientação são dos cursos de Saúde e Agrárias; alguns contam com o apoio familiar.

- Alunos com deficiência intelectual e motora: pedem tutoria e adaptação curricular quanto às avaliações e estágios, principalmente pela dificuldade em acompanhar o ritmo de determinadas disciplinas.

- Alunos com incapacidade orgânica, permanente ou temporária: procuram adaptação curricular quanto às avaliações e estágios, principalmente devido aos tratamentos.

Outra característica relativa ao alunado especial da Unicentro era a predominância da escolha por cursos de Licenciaturas: Pedagogia, História, Geografia, Matemática e Química, e a menor incidência nos cursos de Bacharelado em Administração e Nutrição. Outra tônica observada era a presença de características que compreendiam os Transtornos do Humor em alunos oriundos dos cursos de Saúde e Agrárias. Os alunos eram, então, 
encaminhados para avaliação psiquiátrica e psicológica com o objetivo de ter em mãos um laudo para que, assim, fosse possível dialogar com os departamentos pedagógicos sobre o aproveitamento nas disciplinas.

Dessa forma, o novo programa precisou reconfigurar seu regimento, auxiliado diretamente pela Pró-Reitoria de Ensino, para ampliar seu atendimento a outros nativos da universidade. Esse passo foi definitivamente importante para a política inclusiva organizada pelo Programa de Inclusão e Acessibilidade (PIA). Corroborando a pressuposição de barreiras que poderiam dificultar o processo de ensino-aprendizagem ou de funcionalidade, o regimento manteve a política de atendimento a incapacidades orgânicas permanentes ou temporárias, a deficiências sensoriais e motoras, a transtornos do humor e à superdotação/altas habilidades.

Para a efetivação da permanência do aluno no processo ensinoaprendizagem, o programa transferiu para si os intérpretes alocados no Departamento de Pedagogia, de modo que pôde organizar seus horários para o atendimento de alunos e professores em diferentes setores. A sala do PIA foi remodelada com novos computadores disponibilizados pela direção, mesas de reunião e programas livres de leitores de tela, lupa eletrônica e teclados adaptados.

A ampliação de uma política inclusiva precisava reforçar a concepção de comunidade de aprendizagem no sentido de descentralidade de suas fontes formativas e informativas (Pozo, 2002). Isso exigiu que o PIA inserisse novas fontes de aprendizagem na forma de ações extensionistas para efetivar a maior interação entre os grupos e indivíduos atendidos com a universidade. Com efeito, cada ação criada era o desdobramento de novas aprendizagens de acordo com a demanda dos nativos da Unicentro.

Para os alunos com baixa visão, o serviço de digitalização foi aperfeiçoado tornando-se mais ágil pelo uso de contraste - disposição do texto na folha e tamanho da fonte - e pelo pedido de um aparelho de escaneamento que fizesse a conversão de imagens em texto para impressão e de leitores de tela. Observou-se que o braile somente era utilizado para o ingresso, mas durante o curso os alunos preferiam a ampliação ou o uso de leitor de tela.

Quanto ao atendimento dos alunos com Transtorno do Humor, o programa fazia o encaminhamento do aluno para atendimento psicológico e psiquiátrico nos centros ofertados pela cidade, ou, caso o aluno tivesse algum convênio, para clínicas particulares.

Para desenvolver as atividades do PIA, foi criado um Programa de Extensão Permanente, "Acessibilidade no Ensino Superior", vinculado à Pró-Reitoria de Extensão (Proec), que, com o formato de projeto guardachuva, congrega as diferentes ações extensivas inclusivas dentro de um mesmo plano para que, assim, atendam de forma mais pontual as necessidades de cada grupo ou indivíduo, conforme surja a demanda.

Assim, surgiram projetos de extensão temporários e recorrentes, como o curso preparatório intensivo de Libras (240 horas) para a formação de intérpretes e tradutores. Em razão da necessidade local pela capacitação 
e ampliação do quadro de intérpretes para a comunidade surda interna e externa, esse curso contou com o apoio dos intérpretes, professores de Libras e instrutores surdos. Por esse empenho coletivo, o curso teve seu custo reduzido de forma expressiva. Também se pensou na divulgação da Libras e no acesso a ela como uma nova fonte de aprendizagem, por meio da organização de um projeto de extensão de cursos introdutórios de Libras de 20 horas, semestralmente.

Juntamente ao curso de Ciência da Computação, foi desenvolvido outro projeto de extensão para a capacitação dos técnicos institucionais e do púbico externo sobre "Acessibilidade na Web", visto que ainda é um grande desafio tornar acessíveis programas de gestão institucional ou de páginas virtuais para os usuários de leitor de tela.

Outra ação foi direcionada para o processo ensino-aprendizagem por meio de dados etnográficos educacionais apresentados por funcionários do PIA e intérpretes de Libras. Tornou-se necessário confeccionar uma "Cartilha Explicativa de Medidas Pedagógicas Inclusivas" para orientar os professores quanto a medidas pedagógicas inclusivas. Em geral, são explicações sobre o trabalho de intérprete de Libras, a necessidade do envio com antecedência de materiais bibliográficos para que alunos com deficiência sensorial possam acompanhar apropriadamente, como também sobre o efeito de medicamentos no comportamento dos alunos com Transtornos do Humor.

Além disso, o programa de extensão mantém como ação a preparação de materiais adaptados que possam configurar um banco de informações de disciplinas comuns à totalidade dos cursos de Licenciaturas: Psicologia da Educação e correlatas, Didática e Fundamentos de Educação. A adaptação se dirige a alunos surdos e a alunos cegos ou de baixa visão das Licenciaturas por meio do apoio de materiais bibliográficos extras.

Outros atendimentos foram intensificados para que os departamentos pedagógicos viessem compreender as implicações didático-pedagógicas dos Transtornos do Humor no ensino. Sem corroborar a medicalização do ensino, constatada pelo uso indiscriminado de antidepressivos e ansiolíticos pela comunidade acadêmica, a visita aos departamentos e as conversas com alunos e seus professores tinham como intuito evitar distorções, preconceitos ou descaso quanto a problemas reais que necessitavam de encaminhamentos.

A respeito de algumas situações, principalmente em relação a estágios nas diferentes áreas, o PIA orientava o ensino superior, em adaptação à LDB:

$\S 2^{\circ}$ Os alunos que tenham extraordinário aproveitamento nos estudos, demonstrado por meio de provas e outros instrumentos de avaliação específicos, aplicados por banca examinadora especial, poderão ter abreviada a duração dos seus cursos, de acordo com as normas dos sistemas de ensino. (Brasil. Lei no 9.394, 1996, art. 47).

Isso poderia ser aplicado igualmente a fim de adaptar o currículo para uma prática avaliativa que abarcasse a condição do aluno com necessidade 
específica, dando oportunidade de ele ser avaliado sem o conflito da aprovação ou reprovação por motivos escusos, mas por meio do apoio de uma banca que tenha como pressuposto o aspecto pedagógico sobre o futuro profissional e o aprendizado necessário.

Uma prática discutível seria a prescrição da terminalidade específica no art. 59 da LDB, que enfatiza as oportunidades de aprendizado apropriadas às condições do alunado ou então a restrição no diploma do egresso como mais uma esquiva administrativo-pedagógica em viabilizar sua colação de grau, já que repassa a problemática da aprendizagem para o indivíduo e para a sociedade. Nesse caso, é mister a consulta aos conselhos profissionais para saber o que poderia ou não constar no diploma para seu credenciamento. Tomada como uma medida generalista, a terminalidade específica, ou a restrição no diploma, como a desenhada para o ensino fundamental (Brasil. Lei no 9.394, 1996, arts. 24, 26, 32), não deixaria de ser uma atitude elusiva por parte das instituições de ensino superior para manter a centralidade do processo educativo do ensino superior (Lima; Mendes, 2011).

\section{Considerações finais}

A etnografia educacional e a pesquisa-ação demonstraram a complementação entre a necessária constatação dos grupos, interesses e tensões que atravessam os diferentes setores universitários e a busca por efetivar ações inclusivas como política de cidadania. O desdobramento desse processo precisou, em toda sua evolução, manter uma proximidade com os atores que procuravam auxílio, ao mesmo tempo que deflagrava distorções em relação à atitude de alunos especiais, bem como distorções em relação ao que a universidade poderia executar efetivamente. Isso significou que as barreiras constituintes do cotidiano universitário apreendiam sinais identitários do meio externo, ora como força de vínculo em prol de determinadas adaptações, próprio à comunidade dos surdos, ora como instrumento de destaque para identificar os alunos que precisariam de um acompanhamento diferenciado, quando determinados cursos adotavam uma atitude de proximidade com o PIA.

Observou-se que a justificativa da dificuldade encontrada, em alguns casos, não provinha de um traço identitário - qual seja, apresentar surdez, cegueira ou depressão - mas de algo que atingiria a outros alunos e/ ou a toda comunidade interna. A escuta a respeito do programa que ocorria em espaços institucionais distintos era capacitada para entender como o vínculo a um determinado traço, pessoal ou de grupo, modelava os interesses e reivindicações, sem que, necessariamente, as medidas necessárias fossem restritas a tal particularidade.

Assim, conforme medidas inclusivas eram engendradas junto aos setores, como adaptações de avaliações e outras estratégias funcionais, 
a aprendizagem passava a ser destacada em seu caráter múltiplo, tanto em diferentes fontes quanto em diferentes processos de aquisição. Ao invés de simplificar o ensino superior, isso o tornava mais complexo, mais amplo, porém, apontava, por meio de seus atores, novas concepções, que tornavam as interações e seus vários ambientes uma grande fonte de aprendizagem descentralizada. Tal ambiente auxiliou o PIA a criar novas ações para evidenciar que a noção de comunidade de aprendizagem era um forte instrumental organizativo e pedagógico para a instituição.

Com dois anos de ampliação do programa de inclusão da Unicentro, percebeu-se que as ações ainda precisam ser expandidas para atender outras necessidades específicas que comprometam tanto o sucesso acadêmico quanto funcional da comunidade acadêmica, o que depende da amplitude de adesão de novos setores institucionais e do rompimento de barreiras que mantinham a exclusão, pela historicidade de grupos e indivíduos, próxima à tensão entre luta e caridade, sujeito e vítima.

Ao longo do período, o PIA buscou manter uma proximidade com os departamentos de todos os campi da universidade, enviando memorandos a fim de explicar os serviços e auxílios que estavam à disposição da comunidade, bem como veicular o apelo para que os professores ficassem atentos a alunos que eventualmente apresentassem algum tipo de barreira nas atividades escolares. Baseados na temporalidade do ensino superior - acesso, permanência e sucesso -, o programa desdobrou suas ações na modelação de uma ação extensiva permanente e interventiva para maximizar e direcionar novas ações inclusivas conforme a formação dos alunos configurava novas adaptações. Porém, há ainda problemáticas relativas ao acesso, como o ingresso do aluno com necessidades especiais, que precisariam de ações para auxiliar a capacitação de professores do ensino médio, bem como para auxiliar os próprios alunos em uma melhor preparação para o vestibular.

O diálogo entre as instituições de ensino superior (IES) e os conselhos profissionais poderia auxiliar na seleção de aprendizagens a serem adaptadas, alteradas ou substituídas. Todavia, esse diálogo geralmente é moroso, quando há algum tipo de resposta (Nunes; Carvalho, 2007). Se a avaliação dos conselheiros do Ministério da Educação autoriza os vestibulares praticados, retorna para a instituição toda a responsabilidade em prover meios pedagógicos adaptativos para que os alunos tenham a formação escolhida. Porém, torna-se coerente que o diálogo entre IES, MEC, conselhos profissionais e sociedade possa avaliar quais aprendizagens são necessárias e podem ser adaptadas para questões micro e/ou macro regionais. 


\section{Referências bibliográficas}

BARTH, Fredrik. O guru, o iniciador e outras variações antropológicas. Rio de Janeiro: Contra Capa, 2000.

BISOL, Cláudia Alquati et al. Estudantes surdos no ensino superior. Cadernos de Pesquisa, São Paulo, v. 30, n. 139, p. 147-172, jan./abr. 2010.

BRASIL. Conselho Nacional de Educação (CNE). Conselho Pleno (CP). Resolução CNE/CP no 1, de 18 de fevereiro de 2002. Institui Diretrizes Curriculares Nacionais para a Formação de Professores da Educação Básica, em nível superior, curso de licenciatura, de graduação plena. Diário Oficial da União, Brasília, DF, 04 mar. 2002. Seção 1, p. 8. Disponível em: <http://portal.mec.gov.br/cne/arquivos/pdf/CP012002.pdf>. Acesso em: 10 maio 2010.

BRASIL. Decreto $\mathrm{n}^{\circ}$ 5.296, de 2 de dezembro de 2004. Regulamenta as Leis n. 10.048, de 8 de novembro de 2000, que dá prioridade de atendimento às pessoas que especifica, e 10.098, de 19 de dezembro de 2000, que estabelece normas gerais e critérios básicos para a promoção da acessibilidade das pessoas portadoras de deficiência ou com mobilidade reduzida, e dá outras providências. Diário Oficial da União, Brasília, DF, 13 dez. 2004. Disponível em: < http://www3. dataprev.gov.br/ SISLEX/paginas/23/2004/5296.htm>. Acesso em: 15 out. 2010 .

BRASIL. Instituto Nacional de Estudos e Pesquisas Educacionais Anísio Teixeira (Inep). Censo da Educação Superior 2009. Brasília, DF: Inep, 2010. Disponível em: <http://www.inep.gov.br/superior/censosuperior/ relatorio_tecnico.htm>. Acesso em: 10 abr. 2012.

BRASIL. Lei $n^{\circ} 10.048$, de 8 de novembro de 2000. Dá prioridade de atendimento às pessoas que especifica, e dá outras providências. Diário Oficial da União, Brasília, DF, 9 nov. 2000. Disponível em: <http:// www.planalto.gov.br/ccivil_03/leis/110048.htm>. Acesso em: 15 out. 2010.

BRASIL. Lei no 10.098, de 19 de dezembro de 2000. Estabelece normas gerais e critérios básicos para a promoção da acessibilidade das pessoas portadoras de deficiência ou com mobilidade reduzida, e dá outras providências. Diário Oficial da União, Brasília, DF, 20 dez. 2000. Disponível em: <http://www.planalto.gov.br/ccivil_03/leis/110098.htm>.

BRASIL. Lei no 10.172, de 9 de janeiro de 2001. Aprova o Plano Nacional de Educação e dá outras providências. Diário Oficial da União, 
Brasília, DF, 10 jan. 2001. Disponível em: <http://www.planalto.gov.br/ ccivil_03/leis/leis_2001/110172.htm>.

BRASIL. Lei no 9.394, de 20 de dezembro de 1996. Estabelece as diretrizes e bases da educação nacional. Diário Oficial [da] República Federativa do Brasil, Brasília, DF, 23 dez. 1996. Disponível em: <http:// www.planalto.gov.br/ccivil_03/leis/19394.htm>.

CERTEAU, Michel. A invenção do cotidiano: 1 - artes do fazer. 14. ed. Petrópolis: Vozes, 2000.

CUNHA, Manuela Carneiro da. Cultura com aspas e outros ensaios. São Paulo: Cosac Naify, 2010.

D'ÁVILA, Geruza T. et al. Acesso ao ensino superior e o projeto de "ser alguém" para vestibulandos de um cursinho popular. Psicologia \& Sociedade, Florianópolis, v. 23, n. 3, p. 350-358, 2001.

DURHAM, Eunice Ribeiro. A dinâmica da cultura: ensaios de antropologia. São Paulo: Cosac Naify, 2010.

GLAT, Rosana. Educação especial no contexto da educação inclusiva: diretrizes políticas e ações pedagógicas. Rio de Janeiro: UERJ, 2011. (Financiamento CNPQ - Prociência).

LIMA, Solange Rodovalho; MENDES, Eniceia Gonçalves. Escolarização da pessoa com deficiência intelectual: terminalidade específica e expectativas familiares. Revista Brasileira de Educação Especial, Marilia, v. 17, n. 2, maio/ago. 2011. Disponível em: <http://www.scielo. br/scielo.php?pid=S1413-65382011000200003\&script=sci_arttext $>$. Acesso em: 20 ago. 2012.

MARTINS, Carlos Benedito. O ensino superior brasileiro nos anos 90. São Paulo em Perspectiva, São Paulo, v. 14, n. 1, p. 41-60, 2000. Disponível em: < http://www.scielo.br/pdf/spp/v14n1/9801>.

NUNES, Edson; CARVALHO, Márcia Marques de. Ensino universitário, corporação e profissão: paradoxo e dilemas brasileiros. Sociologias, Porto Alegre, v. 9, n. 17, p. 190-215, jun./jul. 2007. Disponível em: <http://www.scielo.br/pdf/soc/n17/a08n17.pdf >.

OLIVEIRA, Katya Luciane; SANTOS, Acácia Aparecida Angeli dos Santos. Avaliação da aprendizagem na universidade: avaliação da aprendizagem. Psicologia Escolar e Educacional, Campinas, v. 9, n. 1, p. 37-46, 2005. 
POZO, Juan Ignacio. Aprendizes e mestres: a nova cultura da aprendizagem. Porto Alegre: ArtMed, 2002.

SAMPAIO, Helena. O ensino superior no Brasil: o setor privado. São Paulo: FAPESP/HUCITEC, 2000.

SILVA, Jefferson Olivatto da. Educação especial e práticas escolares: novos caminhos pedagógicos. Rio de Janeiro: Multifoco, 2012.

TRIPP, David. Critical incidents in teaching: the development of professional judgement. Londres; Nova York: Routledge, 1993.

Jefferson Olivatto da Silva, doutor em Ciências Sociais pela Universidade Estadual Paulista (Unesp), campus Marília, é docente do Departamento de Pedagogia da Universidade Estadual do Centro-Oeste (Unicentro), Guarapuava, Paraná, Brasil.

jeffcassiel@yahoo.com

Recebido em 22 de agosto de 2013.

Aprovado em 11 de março de 2014. 